\title{
Fusion of Freehand SPECT and Ultrasound to Perform Ultrasound-Guided Fine-Needle Aspiration Cytology of Sentinel Nodes in Head and Neck Cancer
}

\author{
R. de Bree, B. Pouw, D.A. Heuveling, and J.A. Castelijns
}

\begin{abstract}
BACKGROUND AND PURPOSE: Criteria for ultrasound-guided fine-needle aspiration cytology (USgFNAC) for the detection of occult lymph node metastasis in patients with clinically negative head and neck cancer are based on the morphology of cervical lymph nodes. To improve the selection of lymph nodes for USgFNAC, we examined the feasibility of fused freehand single-photon emission tomography ultrasound-guided fine-needle cytology (freehand SPECT-USgFNAC) of sentinel nodes in patients with early stage oral and head and neck skin cancer.
\end{abstract}

MATERIALS AND METHODS: Six patients with early-stage head and neck cancer (4 oral and 2 head and neck skin cancers) and a clinically negative neck who were scheduled for transoral or local excision and a sentinel node procedure underwent USgFNAC and freehand SPECT-USgFNAC preoperatively.

RESULTS: All freehand SPECT sonographic examinations were technically successful in terms of identifying sentinel nodes. All aspirates of sentinel nodes obtained by freehand SPECT-USgFNAC contained substantial radioactivity, confirming puncture of the sentinel nodes. USgFNAC evaluated 13 lymph nodes; freehand SPECT-USgFNAC, 19 nodes; and sentinel node biopsy, 13 nodes. Three sentinel nodes were histopathologically positive and were selected for aspiration cytology by freehand SPECT-USgFNAC, but not by conventional ultrasound. The cytologic examination findings of the aspirations were negative or inconclusive.

CONCLUSIONS: Freehand SPECT ultrasound can identify sentinel nodes and could potentially improve USgFNAC in patients with head and neck cancer by better selection of lymph nodes at highest risk of having metastases (sentinel nodes), but its sensitivity is limited by sampling error and insufficient aspirated material for cytology.

ABBREVIATIONS: $\mathrm{CNO}=$ clinically node-negative; $\mathrm{OSCC}=$ oral squamous cell carcinoma; $\mathrm{SN}=$ sentinel node; $\mathrm{SNB}=$ sentinel node biopsy; $\mathrm{US}=$ ultrasound; USgFNAC = ultrasound-guided fine-needle aspiration cytology

$\mathrm{H}$ ead and neck cancer has a high propensity for metastasizing through the lymphatics to regional lymph nodes rather than spreading hematogenously. It is universally accepted that the neck has to be treated by either surgery with or without adjuvant radiation or chemoradiation or by primary radiation or chemoradiation when lymph node metastases are present.

\footnotetext{
Received February 14, 2015; accepted after revision April 14.

From the Departments of Otolaryngology-Head and Neck Surgery (R.d.B., D.A.H.) and Radiology and Nuclear Medicine (J.A.C.), VU University Medical Center, Amsterdam, the Netherlands; Department of Head and Neck Surgical Oncology (R.d.B.), UMC Utrecht Cancer Center, Utrecht, the Netherlands; and Department of Nuclear Medicine (B.P.), Netherlands Cancer Institute-Antoni van Leeuwenhoek Hospital, Amsterdam, the Netherlands.

This work was supported by VUmc Cancer Center Amsterdam.

Please address correspondence to Remco de Bree, MD PhD, Department of Head and Neck Surgical Oncology, UMC Utrecht Cancer Center, UMCU Utrecht, Heidelberglaan 1000, 3584 CX Utrecht, the Netherlands, PO Box 85500,3508 GA Utrecht, the Netherlands; e-mail: r.debree@umcutrecht.nl

http://dx.doi.org/10.3174/ajnr.A4426
}

In patients with clinically node-negative (cN0) tumors, occult metastases or micrometastases are still present in approximately $30 \%$ of cases. Clinical staging by palpation is typically followed by imaging with CT, MR imaging, positron-emission tomography, ultrasound (US), and/or ultrasound-guided fine-needle aspiration cytology (USgFNAC). ${ }^{1,2}$ USgFNAC is the most reliable of these diagnostic techniques, with a sensitivity of $48 \%-73 \%$ and a specificity approaching $100 \%{ }^{2}$

In an attempt to select the lymph nodes most likely to contain metastases, the sentinel node ( $\mathrm{SN}$ ) concept has been introduced. Sentinel node biopsy (SNB) is a diagnostic staging procedure that is applied in a variety of tumor types, including head and neck skin cancers and oral squamous cell carcinoma (OSCC). The procedure aims to identify the first draining lymph nodes, the SNs that are most likely to have metastases. The histopathologic status of the SN should reflect that of the rest of the nodal basin, and additional treatment of the nodal basin (eg, lymph node dissection) should only be performed in case of metastatic involvement of the $\mathrm{SN} .^{3}$ 
SNB is a reliable diagnostic procedure for staging of the cN0 neck and identifying patients with occult nodal metastatic disease. A recent meta-analysis on SNB in early OSCC showed a pooled sensitivity of $92 \%$ and a negative predictive value of $88 \%-100 \%{ }^{4}$ More recently, a retrospective study of 90 previously untreated patients with early OSCC with a cN0 neck who underwent SNB (only neck dissection after positive findings on $\mathrm{SNB}$ ) was performed: A lymphoscintigraphic identification rate of $98 \%$, a surgical detection rate of $99 \%$, and an upstaging rate of 30\% were found. ${ }^{5}$ SNB has been extensively used in skin cancer, particularly melanoma. ${ }^{6}$

Although less invasive compared with elective neck dissection, SNB is still a surgical procedure. Moreover, SNB is more complex and costly than USgFNAC. Therefore, in most centers in which SNB is used, patients are selected for SNB after negative findings of USgFNAC. USgFNAC may thus avoid unnecessary SNB but would also decrease the risk of false-negative SNB when gross metastatic involvement of the node prohibits tracer uptake. If the sensitivity of USgFNAC can be improved, the better yield of this procedure as a first-line technique may reduce the number of SNBs without jeopardizing oncologic outcome. Additionally, SNB may result in fibrosis, making subsequent neck dissection more difficult. Finally, patients can be scheduled immediately for neck dissection and do not have to wait for the results of the time-consuming and labor-intensive SN procedure.

Criteria for USgFNAC in patients with cN0 OSCC are based on the morphology of the cervical lymph nodes. Lymph nodes with a minimal axial diameter of $>4 \mathrm{~mm}$ in level II of the neck and $3 \mathrm{~mm}$ in other levels of the neck are selected for USgFNAC to obtain a high sensitivity. ${ }^{7}$ Inaccurate results of USgFNAC are attributed to an absence of enlarged lymph nodes, aspiration of the wrong lymph node, failure of cytologic analysis due to insufficient material for cytopathologic diagnosis, or the presence of micrometastases in parts of the lymph nodes not aspirated (sampling error). Whereas the conventional selection is based on standard drainage patterns and lymph node size and morphology, lymphatic mapping identifying the SN may improve selection of the lymph nodes with the highest risk of having metastases to be aspirated.

Freehand single-photon emission tomography is an innovative technique aiming to guide the physician to the exact localization of the radioactive area of interest (eg, the SN). Freehand SPECT is a $3 \mathrm{D}$ tomographic technique based on the imaging concepts of SPECT, but with the major difference being that it is based on data acquisition by hand-held detectors instead of gantrybased gamma cameras. The technology is designed to use a conventional gamma probe or hand-held gamma camera for the detection of radiation and positioning systems to determine the position of the detector relative to the patient. On the basis of the integration of the acquired set of detector readouts and their position and orientation, the system is capable of generating 3D nuclear images similar to a SPECT image, thus providing visualization of the SN at any time. ${ }^{8,9}$ Freehand SPECT can be integrated with video or other imaging modalities. ${ }^{10}$ Recently, the fusion of these 3D nuclear images with US, making SN visualization on US possible, was introduced. ${ }^{11,12}$ In this setup, functional (fully 3D freehand SPECT) and anatomic (2D ultrasound) information are combined in real-time.

We performed a pilot study to examine the feasibility of freehand SPECT-USgFNAC of SNs in patients with early OSCC and head and neck skin cancer.

\section{MATERIALS AND METHODS Patient Selection}

Six patients with early-stage head and neck cancer (4 OSCCs and 2 head and neck skin cancers) with a cN0 neck who were scheduled for transoral or local excision and an SN procedure underwent USgFNAC and freehand SPECT-USgFNAC preoperatively. This study was approved by the institutional review board.

\section{USgFNAC}

In routine USgFNAC, lymph nodes with a minimal axial diameter of $>4 \mathrm{~mm}$ in level II of the neck and $3 \mathrm{~mm}$ in other levels of the neck, absence of an echogenic hilus, presence of coagulation necrosis, and presence of eccentric cortical hypertrophy or hypoechoic sonomorphology were selected for puncture. USgFNAC was obtained by using a syringe holder (Cameco, Täby, Sweden) and a 22-ga needle (Terumo, Sommerset, New Jersey). Lymph nodes were punctured twice. The radiologist performing this procedure had 25 years' experience, and the cytopathologist, $>15$ years.

\section{Lymphoscintigraphy}

The SN procedure was performed according the guidelines of the European Association of Nuclear Medicine and the European Sentinel Node Trial group, ${ }^{3}$ within 1 week following USgFNAC. In the 24-hour period before surgery $100 \mathrm{MBq}$ (divided over 4 aliquots of $0.15-0.20 \mathrm{~mL}$ each) of technetium Tc99m-labeled nanocolloid (NanoColl; GE Healthcare, Eindhoven, the Netherlands) was injected peritumorally. Directly following injection, dynamic and planar lymphoscintigraphic images were acquired followed by SPECT-CT imaging.

\section{Freehand SPECT-USgFNAC}

After complete lymphoscintigraphy (including SPECT-CT), patients underwent freehand SPECT-USgFNAC. The freehand SPECT system (declipse SPECT; SurgicEye, Munich, Germany) combines a hand-held gamma probe system (Crystal Probe; Crystal Photonics, Berlin, Germany; first patient) or a hand-held gamma camera system (CrystalCam; Crystal Photonics; patients 2-6) with an infrared optical tracking system and an integrated data processing unit. To reference a common coordinate system, we taped a configuration of optical and magnetic markers on the sternum or head and used it to determine the position of the patient (see below). The gamma detectors were calibrated to include the $140 \mathrm{keV}$ (peak) of technetium Tc99m with an energy window of $40 \mathrm{keV}$ for the probe and $10 \mathrm{keV}$ for the camera. The collimator opening of the probe was approximately $40^{\circ}$. The gamma camera used a hand-held, semiconductor solid-state scintillator and a solid-state detector-based handheld gamma camera parallel collimator with $16 \times 16$ holes with dimensions of $2.16 \times$ $2.16 \mathrm{~mm}^{2}$, resulting in an FOV of $40 \times 40 \mathrm{~mm}^{2}$. See Fig 1 for the clinical setup. 

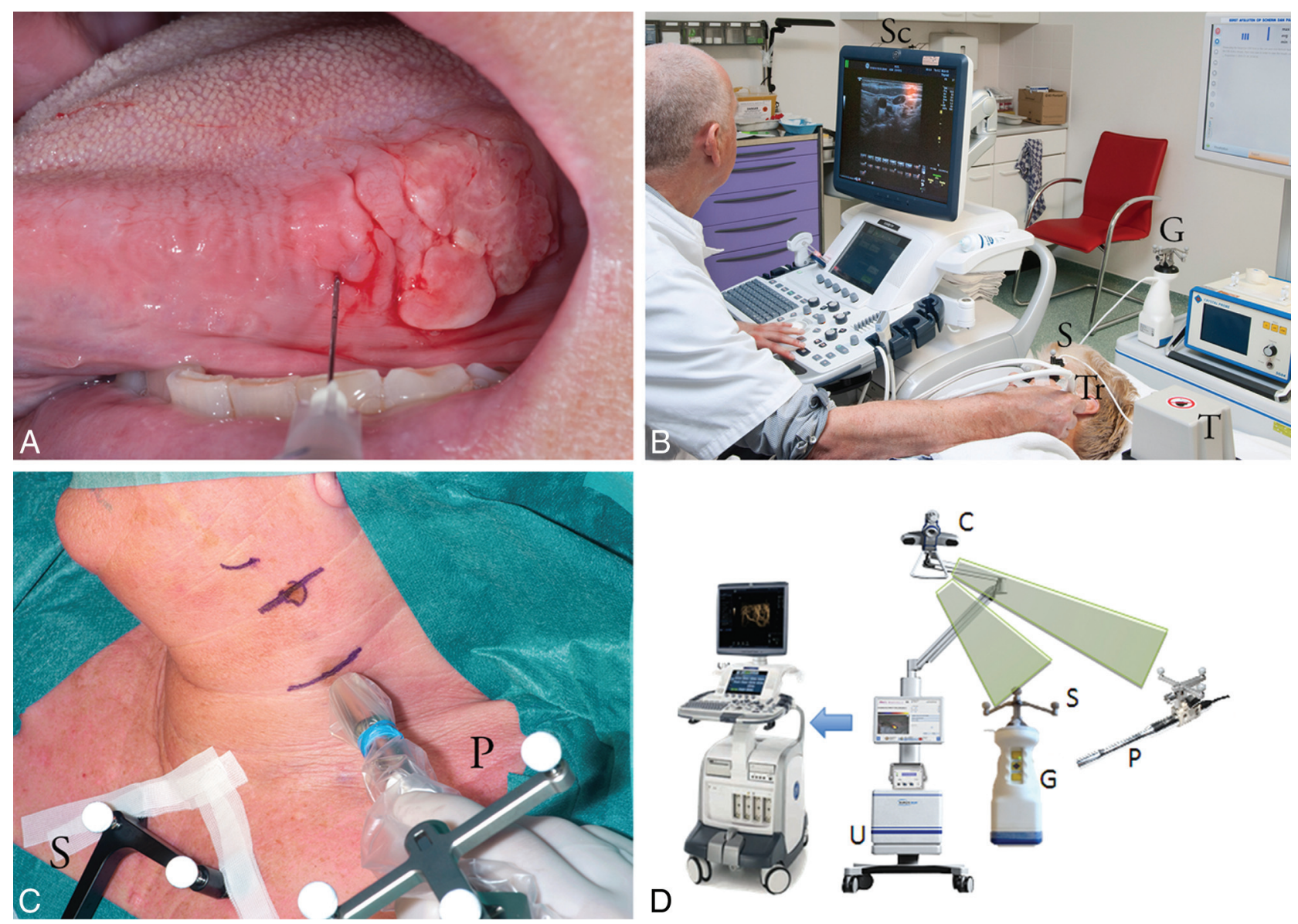

FIG 1. Patient 2 with a T2 lateral tongue carcinoma. A, Peritumoral injection of technetium TC99m labeled-nanocolloid. B, Freehand SPECT-US. Note the optical markers on the freehand gamma camera $(G)$, the transmitter generating the magnetic field (T), the electromagnetic sensor attached to the US transducer (Tr), and the shared optical and electromagnetic sensor (S) affixed to the head of the patient. The optical camera is not shown in this image. A fused SPECT-US image is on the screen (Sc) after SPECT data have been loaded onto the US machine in DICOM format by using a USB stick. C, Use of freehand SPECT during surgery. Note the optical sensors on the probe (P) and the sternum of the patient (S). D, Freehand SPECT and US system with infrared optical tracking system (camera [C], detectors [G+P], and sensors [S]) and a data processing unit (U).

To obtain 3D images, we separately scanned each area of preoperatively identified SN by moving the gamma probe or camera in different directions over the skin. Scanning was stopped when the complete volume reached a sufficient information attenuation (as indicated by the system; commonly 1 minute) and thus a sufficient image quality.

US was performed by using a commercially available US system (LOGIQ E9; GE Healthcare, Milwaukee, Wisconsin) configured with Volume Navigation and an ML6-15 US transducer. An electromagnetic transmitter was placed near the imaging area, and a pair of electromagnetic sensors was attached to a bracket that connects to the US transducer. The position-sensing equipment allowed the US device to track the position of the transducer, and therefore the image position, within the electromagnetic field.

To ensure the correct positioning and alignment of both tracking systems, we used the merged common optical/electromagnetic patient reference as mentioned above. The combination of 2 independent tracking systems allowed automatic coregistration of SPECT and US images without the need of user-interactionlike point-based registration (eg, by using anatomic landmarks or surface scanners) as used in commercial surgical navigation suites. As the US image is moved, the freehand SPECT image follows its movement in real-time. The images are displayed side by side or in blended, overlapping format.

Specific attention was paid to avoid movement of the head and neck during the procedure to minimize deviations in the fused images. The head of the patient lay in a holder normally used in the operating room for patients undergoing head and neck surgery.

USgFNAC was performed on the SN visualized on the fused images. The radiologist who performed freehand SPECTUSgFNAC was blinded to the results of planar lymphoscintigraphy and SPECT-CT. Freehand SPECT-US-guided aspirations were performed by using a syringe holder (Cameco) and a $0.6 \times 25 \mathrm{~mm}$ needle (Terumo). After visualization of the needle inside the lymph node, we started aspiration and continued it by moving the needle gently up and down. Aspirates were checked for radioactivity by counting 60 seconds in a well-counter (1282 Compugamma; LBK Wallac, Turku, Finland) and sent for cytopathologic examination.

\section{Sentinel Node Biopsy}

At the start of surgery, $1 \mathrm{~mL}$ of Patent Blue $\mathrm{V}$ dye diluted 1:3 (volume to volume) in water was injected at 4 equally spaced points to completely surround the tumor. Subsequently, the po- 
Primary tumors and results of USgFNAC, aspiration cytology guided by fused images of freehand SPECT-USgFNAC, and SNB of 6 patients with early-stage head and neck cancer

\begin{tabular}{|c|c|c|c|c|c|c|c|c|c|c|}
\hline \multirow[b]{2}{*}{ Patient } & \multirow[b]{2}{*}{ Primary Tumor } & \multicolumn{3}{|c|}{ USgFNAC } & \multicolumn{3}{|c|}{ Freehand SPECT-USgFNAC } & \multicolumn{3}{|c|}{ SNB } \\
\hline & & Level & Size (mm) & Cytopath & Level & Size $(\mathrm{mm})^{\mathrm{a}}$ & Counts $^{b}$ & Cytopath & & Histopath \\
\hline \multirow[t]{4}{*}{1} & $\mathrm{~T} 7$ tongue $\mathrm{L} S \mathrm{SCC}$ & & & & $\| \mathrm{L}$ & 2.5 & 52710 & - & II L & - \\
\hline & & & & & $\| \mathrm{L}$ & 1.5 & 555 & - & II L & - \\
\hline & & & & & $\| \mathrm{L}$ & 1.5 & 35340 & - & II L & - \\
\hline & & & & & & & & & III R & - \\
\hline \multirow[t]{3}{*}{2} & $\mathrm{~T} 2$ tongue $\mathrm{L}$ SCC & $\| \mathrm{L}$ & 6.2 & - & $\| \mathrm{L}$ & 4.8 & 3051 & - & II L & - \\
\hline & & IIIL & 7.4 & - & IIIL L & 7.1 & 40151 & - & & \\
\hline & & IVL & 5.1 & - & IVL & 4.8 & 36354 & - & IV L & - \\
\hline \multirow[t]{4}{*}{3} & T2 ala nasi R Merkel cell carcinoma & & & & I R & 4.0 & 2847 & 0 & IR & $+(\mathrm{i}+)$ \\
\hline & & & & & I R & 4.3 & 208 & - & & \\
\hline & & $\| R$ & 6.4 & - & $\| R$ & 6.6 & 204 & 0 & & \\
\hline & & & & & I L & 4.9 & 409 & 0 & & \\
\hline \multirow[t]{2}{*}{4} & $\mathrm{~T} 1$ auricle R melanoma & $P R$ & 2.8 & - & P R & 2.3 & 74944 & - & $P R$ & $+(\mathrm{mi})$ \\
\hline & & & & & $\| R$ & 2.4 & 241233 & - & $\| \mathrm{R}$ & - \\
\hline \multirow[t]{5}{*}{5} & T2 floor of mouth L SCC & I R & 4.5 & - & I R & 2.8 & 2782 & - & IR & - \\
\hline & & & & & I R & 5.8 & 6707 & - & & \\
\hline & & I L & 4.9 & - & I L & 3.9 & 2080 & - & IL & - \\
\hline & & I L & 4.4 & - & I L & 3.9 & 3124 & - & & \\
\hline & & & & & I L & 4.5 & 553 & - & & \\
\hline \multirow[t]{6}{*}{6} & $\mathrm{~T} 1$ tongue $\mathrm{LSCC}$ & R II & 4.8 & - & & & & & & \\
\hline & & L I & 4.5 & - & L I & 4.2 & 207518 & - & LI & - \\
\hline & & L I & 4.5 & - & & & & & & \\
\hline & & L I & 4.5 & - & & & & & & \\
\hline & & L II & 5.9 & - & & & & & & \\
\hline & & & & & L II & 2.8 & 45942 & - & L II & $+(\mathrm{mi})$ \\
\hline
\end{tabular}

Note:-SCC indicates squamous cell carcinoma; Cytopath, cytopathologic examination; Histopath, histopathologic examination; L, left; R, right; P, in parotid gland; i+, isolated tumor cells; mi, micrometastasis; -, tumor negative; 0 , inconclusive; + tumor positive.

a Size in minimal axial diameter.

${ }^{\mathrm{b}}$ Counts per 60 seconds.

sition of the SN was verified by using the freehand SPECT system before the skin incision was made. The $3 \mathrm{D}$ navigation modus provides information about the direction and distance of the SN in relation to the tip of the gamma probe and could be displayed in real-time during the procedure. After excision of the $\mathrm{SN}$, the same area was scanned once more and compared with the primary scan on-screen before excision to confirm removal of all SNs.

Histopathologic examination of SNs consisted of step-serial sectioning with an interval of $150-250 \mu \mathrm{m}$ of the entire lymph node. Of each level, staining with hematoxylin-eosin and pan Cytokeratin Antibody (AE 1/3) was performed. Occult metastases were differentiated into isolated tumor cells $(<0.2 \mathrm{~mm})$, micrometastasis $(>0.2 \mathrm{~mm}$ and $\leq 2 \mathrm{~mm})$, or macrometastasis $(>2$ $\mathrm{mm}$ ). If a nodal tumor deposit was proved by SNB, subsequent neck dissection was performed during a second surgical procedure.

For topographic evaluation, the lymph nodes were scored according to the universally used neck level classification. ${ }^{13}$

\section{RESULTS}

All freehand SPECT-US examinations were technically successful in terms of identifying SNs. Deviations of the fused freehand SPECT and US images were limited to a few millimeters, not precluding selection of lymph nodes for freehand SPECTUSgFNAC. All aspirates obtained by freehand SPECT-USgFNAC contained substantial radioactivity, confirming the puncture of the SNs. The results of the USgFNAC, freehand SPECTUSgFNAC, and SNB are summarized in the Table.

Overall 13 lymph nodes were detected as suspicious and sam-

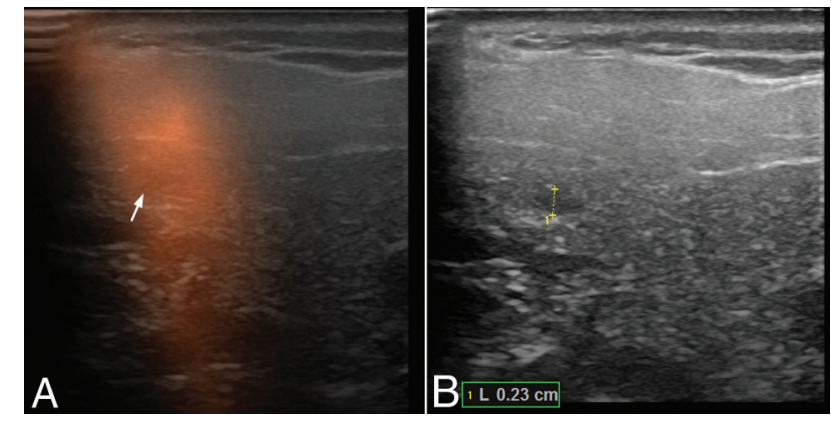

FIG 2. Freehand SPECT-US $(A)$ and US-only image $(B)$ of a sonographically unremarkable (nonsuspicious) sentinel lymph node of $2.3 \mathrm{~mm}$ with micrometastasis in the right parotid gland in patient 4 .

pled on the basis of US alone, and no tumor deposits were found in these nodes. Four of these 13 nodes (all in the last patient) were not SNs as determined by freehand SPECT-US or SNB. Freehand SPECT-US selected 10 (sentinel) lymph nodes for aspiration, which had not been selected by US-only, mainly because the diameter of these nodes was below the selection limit (see, for example, Figs 2 and 3). Freehand SPECT-US also enabled sampling of 7 nodes not resected during the surgical SNB. One negative SN that was not identified by freehand SPECT-US was resected during SNB. Although none of the freehand SPECTUSgFNAC aspirates were positive for lymph node metastases, all 3 positive SNs were selected for puncture by freehand SPECT-US and not by US-only. One SN contained isolated tumor cells, and the other 2 positive SNs contained micrometastasis $(0.2$ and 0.3 $\mathrm{mm}$ ). Patients 3 and 4 had no additional lymph node metastases, 

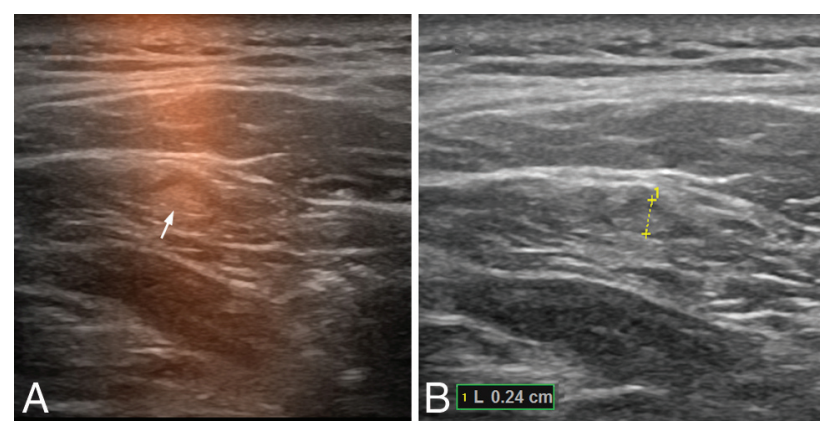

FIG 3. Freehand SPECT-US $(A)$ and US-only image (B) of a sonographically unremarkable (nonsuspicious) pathologically tumornegative sentinel lymph node of $2.4 \mathrm{~mm}$ in level II on the right side in patient 4.

while patient 6 had 2 additional micrometastatic (nonsentinel) lymph nodes in the neck dissection specimen. During follow-up (including USgFNAC every 3 months) of at least 6 months, none of the patients developed a recurrence in the neck.

\section{DISCUSSION}

The present study is the first to report on freehand SPECTUSgFNAC in patients with head and neck cancer, to our knowledge. Freehand SPECT-US mapping of SNs is feasible in patients with early head and neck cancer. Although freehand SPECTUSgFNAC revealed no metastasis, freehand SPECT-US selected the metastatic lymph nodes correctly, whereas US-only did not select these lymph nodes. Moreover, freehand SPECT-USgFNAC allowed evaluation of SNs not identified during SNB (eg, due to blocked drainage by tumor deposits or shinethrough of the injection site, which could reduce the false-negative rate of $\mathrm{SNB}$ ).

Findings of freehand SPECT-USgFNAC were false-negative in 3 patients, probably due to sampling error and the limited amount of aspirated material (insufficient material for diagnosis) because these 3 lymph nodes contained only isolated tumor cells or micrometastasis. Although polymerase chain reaction techniques may decrease the number of inconclusive diagnoses, ${ }^{14}$ sampling error will be inherent in aspiration instead of excisional biopsy of the SN.

A few studies reported on USgFNAC of SNs in early oral cancer. Colnot et $\mathrm{al}^{15}$ reported in 2001 the initial experiences of $\mathrm{VU}$ University Medical Center in 12 patients with oral and oropharyngeal cancer and a cN0 neck. After visualization of the SN, the position was marked on the overlying skin with the use of a pointof-source ${ }^{57} \mathrm{Co}$ marker and was confirmed with a gamma probe. After preparation of the cytologic smears, they counted residues of the aspirates from SNs in a liquid scintillation counter to confirm correct aspiration. Cytologic examination of the aspirated SNs revealed lymph node metastases in 6 patients who underwent neck dissection. In the remaining patients who underwent only transoral excision, 1 false-negative result was observed. They concluded that this combined approach is expected to improve the detection of occult lymph node metastases. ${ }^{15}$

In a further study, Nieuwenhuis et a ${ }^{16}$ reported in 2002 that in 39 patients with early oral and oropharyngeal squamous cell carcinoma undergoing conventional and SN-guided USgFNAC, 11 additional lymph nodes were aspirated because of the SN proce- dure. Because these lymph nodes were all tumor-negative or contained insufficient material at cytologic examination, no additional value of $\mathrm{SN}$ aspiration could be demonstrated at that time. ${ }^{16}$ In the aforementioned studies, aspiration of radioactivityonly does not prove that the real SN has been aspirated because second-echelon nodes can become radioactive. In the last decade, $\mathrm{SN}$ identification has been improved. In the aforementioned studies, no SPECT-CT has been used. SPECT-CT may be especially helpful in the identification and localization of SNs close to the injection site and in differentiation of SNs and second-echelon nodes. Moreover, in the study of Nieuwenhuis et al, ${ }^{16}$ late images were only obtained in 9 of 39 patients, potentially missing SNs in oral cavity tumors other than the lateral tongue and floor of mouth and contralateral SNs in or near midline tumors. ${ }^{17}$

Höft et $\mathrm{al}^{18}$ reported on 16 patients diagnosed with oral, oropharyngeal, or dermal squamous cell carcinoma who had been staged as N0 and who underwent lymphoscintigraphy to localize SNs and USgFNAC on SNs before elective neck dissection. In 14 of 16 patients, an SN could be visualized. Seventeen ipsilateral and 4 contralateral nodes were identified as SNs. No gamma probe was used. In 9 of these $21 \mathrm{SNs}$, it was difficult to differentiate the SN from other lymph nodes in close proximity by US. In 6 of these 14 patients, lymph node metastases were found in the neck dissection specimen, and all patients had at least macrometastases. In only 1 of these 6 patients was metastasis detected by USgFNAC of the SN. ${ }^{18}$ In this study, it is debatable whether without the use of the gamma probe and confirmation of radioactivity in the aspirate, the real SNs were sampled.

Improvement of USgFNAC by aspiration of the real SN can probably increase the sensitivity of the detection of occult lymph node metastasis, but it cannot address the problem of lymph nodes too small for aspiration, insufficient aspirated material, and sampling error. However, any yield in the detection of occult lymph node metastasis by USgFNAC will reduce the number of SNBs needed to give patients with early OSCC the best prognosis without unnecessary extensive diagnostic procedures.

The first clinical results of freehand SPECT have been reported in patients with breast cancer. ${ }^{19}$ In head and neck cancer, initial studies described the feasibility of this technique. ${ }^{20-23}$ A recent study in 66 patients with early OSCC confirmed that the use of the freehand SPECT system is feasible in the intraoperative detection of sentinel nodes in early-stage oral cancer. Moreover, freehand SPECT provides helpful information facilitating the SN biopsy procedure in a quarter of cases. ${ }^{24}$ Freehand SPECT has also been used successfully in malignant melanoma to facilitate the detection and resection of SNs. ${ }^{25}$

Freehand SPECT-US fusion combines the advantages of functional and anatomic information. Freesmeyer et $\mathrm{al}^{11,12}$ showed that freehand SPECT-US was feasible and technically successful in patients with breast cancer, melanoma, and thyroid disease. However, some technical limitations were shown in freehand SPECT quality and fusion precision. ${ }^{23,24}$ The use of a hand-held gamma camera instead of a gamma probe and proper stabilization of the neck as shown in this preliminary study seem to overcome these difficulties. Recently, it has been shown that freehand SPECT-USguided needle biopsy of sentinel lymph nodes in the axilla is feasible. ${ }^{26}$ In the present study, we present the first results of free- 
hand SPECT-USgFNAC in 6 patients with early-stage head and neck cancer.

Limitations of this study are the small number of patients included and the lack of pathologically positive freehand SPECT-USgFNAC findings, but the concept and feasibility of sentinel node identification and aspiration by freehand SPECT-USgFNAC are shown. Larger studies are needed to determine the accuracy of this new technique. As a potential pitfall, because the neck is nonrigid, extra attention must be paid to perform the different examinations in positions as similar as possible. A holder for fixation of the head would be helpful.

\section{CONCLUSIONS}

Freehand SPECT-US can identify SNs and could improve USgFNAC in patients with head and neck cancer by better selection of lymph nodes at the highest risk of having metastases, but its sensitivity is limited by sampling error and insufficient aspirated material for cytology. Nevertheless, it can potentially reduce the need for SNB, currently the most sensitive technique for the detection of occult lymph node metastases, in patients with head and neck cancer by selecting patients directly for therapeutic neck dissection. Larger studies are needed to assess the additional value of freehand SPECT-USgFNAC.

\section{ACKNOWLEDGMENTS}

The authors thank SurgicEye GmbH and GE Healthcare for contributing the hardware and training needed to perform these studies.

\section{REFERENCES}

1. Liao LJ, Lo WC, Hsu WL, et al. Detection of cervical lymph node metastasis in head and neck cancer patients with clinically NO neck-a meta-analysis comparing different imaging modalities. BMC Cancer 2012;12:236 CrossRef Medline

2. De Bree R, Takes RP, Castelijns JA, et al. Advances in diagnostic modalities to detect occult lymph node metastases in head and neck squamous cell carcinoma. Head Neck 2014 Jun 21. [Epub ahead of print] CrossRef Medline

3. Alkureishi LW, Burak Z, Alvarez JA, et al; European Association of Nuclear Medicine Oncology Committee, European Sentinel Node Biopsy Trial Committee. Joint practice guidelines for radionuclide lymphoscintigraphy for sentinel node localization in oral/oropharyngeal squamous cell carcinoma. Eur J Nucl Med Mol Imaging 2009; 36:1915-36 CrossRef Medline

4. Govers TM, Hannink G, Merkx MA, et al. Sentinel node biopsy for squamous cell carcinoma of the oral cavity and oropharynx: a diagnostic meta-analysis. Oral Oncol 2013;49:726-32 CrossRef Medline

5. Den Toom IJ, Heuveling DA, Flach GB, et al. Sentinel node biopsy for early-stage oral cavity cancer: the VU University Medical Center experience. Head Neck 2015;37:573-78 CrossRef Medline

6. Morton DL, Thompson JF, Cochran AJ, et al; MSLT Group. Final trial report of sentinel-node biopsy versus nodal observation in melanoma. N Engl J Med 2014;370:599-609 CrossRef Medline

7. van den Brekel MW, Castelijns JA, Snow GB. The size of lymph nodes in the neck on sonograms as a radiologic criterion for metastasis: how reliable is it? AJNR Am J Neuroradiol 1998;19:695-700 Medline

8. Wendler T, Hartl A, Lasser T, et al. Towards intra-operative 3D nuclear imaging: reconstruction of $3 \mathrm{D}$ radioactive distributions using tracked gamma probes. Med Image Comput Comput Assist Interv 2007;10(pt 2):909-17 Medline
9. Matthies P, Gardiazabal J, Okur A, et al. Mini gamma cameras for intra-operative nuclear tomographic reconstruction. Med Image Anal 2014;18:1329-36 CrossRef Medline

10. Matthies P, Okur A, Wendler T, et al. Combination of intra-operative freehand SPECT imaging with MR images for guidance and navigation. Conf Proc IEEE Eng Med Biol Soc 2013;2013:3383-86 CrossRef Medline

11. Freesmeyer M, Winkens T, Opfermann T, et al. Real-time ultrasound and freehand-SPECT: experiences with sentinel lymph node mapping. Nuklearmedizin 2014;53:259-64 CrossRef Medline

12. Freesmeyer M, Opfermann T, Winkens T. Hybrid integration of real-time US and freehand SPECT: proof of concept in patients with thyroid diseases. Radiology 2014;271:856-61 CrossRef Medline

13. Robbins KT, Medina JE, Wolfe GT, et al. Standardizing neck dissection terminology: Official Report of the Academy's Committee for Head and Neck Surgery and Oncology. Arch Otolaryngol Head Neck Surg 1991;117:601-05 CrossRef Medline

14. Nieuwenhuis EJ, Jaspars LH, Castelijns JA, et al. Quantitative molecular detection of minimal residual head and neck cancer in lymph node aspirates. Clin Cancer Res 2003;9:755-61 Medline

15. Colnot DR, Nieuwenhuis EJ, van den Brekel MW, et al. Head and neck squamous cell carcinoma: US-guided fine-needle aspiration of sentinel lymph nodes for improved staging -initial experience. $R a$ diology 2001;218:289-93 CrossRef Medline

16. Nieuwenhuis EJ, Castelijns JA, Pijpers R, et al. Wait-and-see policy for the N0 neck in early-stage oral and oropharyngeal squamous cell carcinoma using ultrasonography-guided cytology: is there a role for identification of the sentinel node? Head Neck 2002;24: 282-89 CrossRef Medline

17. Heuveling DA, Flach GB, van Schie A, et al. Visualization of the sentinel node in early-stage oral cancer: limited value of late static lymphoscintigraphy. Nucl Med Commun 2012;33:1065-69 CrossRef Medline

18. Höft S, Muhle C, Brenner W, et al. Fine-needle aspiration cytology of the sentinel lymph node in head and neck cancer. J Nucl Med 2002; 43:1585-90 Medline

19. Wendler T, Hermann K, Schnelzer A, et al. First demonstration of 3-D lymphatic mapping in breast cancer using freehand SPECT. Eur J Nucl Med Mol Imaging 2010;37:1452-61 CrossRef Medline

20. Heuveling DA, Karagozoglu KH, van Schie A, et al. Sentinel node biopsy using 3D lymphatic mapping by freehand SPECT in early stage oral cancer: a new technique. Clin Otolaryngol 2012;37:89-90 CrossRef Medline

21. Mandapathil M, Teymoortash A, Heinis J, et al. Freehand SPECT for sentinel lymph node detection in patients with head and neck cancer: first experiences. Acta Otolaryngol 2014;134:100-04 CrossRef Medline

22. Bluemel C, Herrmann K, Müller-Richter U, et al. Freehand SPECTguided sentinel lymph node biopsy in early oral squamous cell carcinoma. Head Neck 2014;36:E112-16 CrossRef Medline

23. Bluemel C, Herrmann, Kübler A, et al. Intraoperative 3-D imaging improves sentinel lymph node biopsy in oral cancer. Eur J Nucl Med Mol Imaging 2014;41:2257-64 CrossRef Medline

24. Heuveling DA, van Weert S, Karagozoglu KH, et al. Evaluation of the use of freehand SPECT for sentinel node biopsy in early stage oral carcinoma. Oral Oncol 2015;51:287-90 CrossRef Medline

25. Mihaljevic AL, Rieger A, Belloni B, et al. Transferring innovative freehand SPECT to the operating room: first experiences with sentinel lymph node biopsy in malignant melanoma. Eur J Surg Oncol 2014;40:42-48 CrossRef Medline

26. Okur A, Hennersperger C, Runyan B, et al. FhSPECT-US guided needle biopsy of sentinel lymph nodes in the axilla: is it feasible? Med Image Comput Comput Assist Interv 2014;17(pt 1): 577-84 Medline 